\title{
Investigating social motivations, opportunity and ability to participate in communities of virtual co-creation
}

\author{
Debora Bettiga $^{1 \mathrm{a}}$, Lucio Lambertia ${ }^{\mathrm{a}}$, Giuliano Noci ${ }^{\mathrm{a}}$

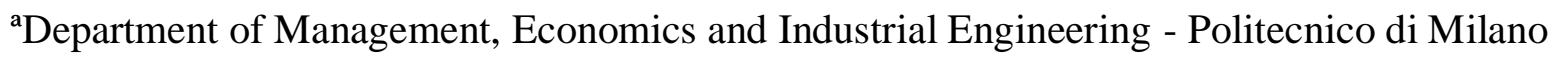 \\ Via Lambruschini 4B - 20156 Milan (Italy) Phone: +39 0223992816 \\ Corresponding author: ${ }^{1}$ debora.bettiga@ polimi.it
}

\begin{abstract}
Communities of virtual co-creation are emerging as a new form of consumer engagement, where through a collaborative and interactive process, ideas and knowledge from consumer are applied differently to create new value for the consumers themselves, the company and all stakeholders. The aim of this paper is to explore the drivers, namely motivation, opportunity and ability, of consumer willingness to participate in communities of virtual co-creation. The role of social motivations, i.e. altruism and social reputation, particularly relevant inside online communities, is investigated. Data were collected through an online survey on 180 consumers from diverse nationalities. The unit of analysis was a virtual co-creation activity for food products. Findings show that consumer motivation and ability have a relevant influence on willingness to participate in co-creation projects, while opportunity has not. In particular, ability showed to be the most relevant factor, suggesting that virtual co-creation initiatives should be properly designed to facilitate the engagement of consumers. Further, results indicate that consumers' motivations are driven by both altruism and social reputation, where altruism plays a greater role. This confirms that social relations are key motivational drivers in virtual communities, where value is created through interaction with like-minded people, exchange of information and experiences, provision of support.
\end{abstract}

Keywords: Co-creation; Virtual Communities; New Product Development; Motivation-OpportunityAbility; Altruism; Social Reputation; 


\section{INTRODUCTION}

Virtual co-creation in new product development (NPD) has established as an important form of consumer participation in value creation along with firms. Co-creation in NPD is defined as "a collaborative NPD activity in which customers actively contribute and/or select the content of a new product offering" (O'Hern \& Rindfleisch 2009, p.4). The development of ICT-based platforms, diminishing the costs for companies to manage large-scale co-creation activities (Fuller, 2006) and enabling a broadly, richly and speedily interaction with and among consumers (Sawhney, 2005; Brodie et al., 2013), has incentivized the naissance of virtual communities of consumers that participate in joint innovation activities. This collaborative innovation enables different levels of customer involvement (Sawhney, 2005). It is directed toward the development of new or improved products created from the integration of knowledge and skills from multiple consumers through social exchange (Roberts, Hughes and Kertbo, 2014). Here the role of consumers is to provide ideas for the development of new products or services, but also provide help in the design phase, judge other ideas, participate in the definition of the price or the promotion. In virtual communities, consumers can vote for the best ideas, leave their comments, and suggest improvements. Firms, on their side, provide consumers with the opportunity to learn, to interact with a community of passionate, to build longlasting relationships with like-minded people and to gain social recognition. For instance, Domino’s Pizza, a US company, launched the "Create-your-own pizza campaign" enabling consumers to create their own pizza through an online platform (Merrilees, 2016). The brand Chipsy launched the initiative "Which one is your Chipsy flavour?" gathering more than 120.000 ideas and finally producing the three winning flavours (Orcik, Teodora and Freund, 2013). Wrigley, producing and globally marketing chewing gums, engaged consumers in the ideation of a new flavour for the product "Extra Professional Mints" and introduced the winning flavour on the market (https://company.trnd.com/en/products-solutions/co-creation-campaigns).

Participation in co-creation activities may provide several benefits to consumers (Sawhney and Prandelli, 2000) such as cognitive, hedonic, social integrative and personal integrative (Vernette and Hamdi-Kidar, 2013). Consumers can meet and interact with like-minded people (Füller, 2010), offer information, discuss about prior experiences but also benefit from the development of new or improved products that satisfy their and community needs or problems. Individuals, by sharing experiences, acquiring cognitive competencies and participating in the development of new products, influence value-in-exchange and value-in-use (Lusch and Vargo, 2006). The opportunity to help other consumers, belonging to a community, and being recognized and valued by like-minded people increases consumer engagement and social utility (Bock et al., 2005; Casaló, Flavián and Guinalíu, 
2010; Kwon and Wen, 2010). Through collective effort, members of the community can create and co-create value for themselves, for other consumers and for the firm, extending the co-creation benefits to the society as a whole (Brodie et al., 2013). In communities of virtual co-creation, indeed, the social and interpersonal benefits, such as recognition from peers and status inside a community may be relevant incentives to participation. Such communities allow consumers to develop stronger connections with firms as well, that can gather precious information on consumers expectations, needs and satisfaction with the current offer in order to improve products and services accordingly (Hoyer et al., 2010; van Dijk, Antonides and Schillewaert, 2014). Successful processes lead to the development of products or services able to satisfy needs not yet fulfilled by the market, to improve the quality of the current offer or satisfy new consumer segments, with benefits for the society as a whole.

Understanding and tapping into co-creator motivations and reduce constraints is the first step to engage consumers in the value exchange. Only relatively few consumers, indeed, have the willingness to be involved or the skills and knowledge to participate in the product development processes (Etgar, 2008). Despite prior studies identified consumer segments more willing to co-create (Hoffman, Kopalle and Novak, 2010; Gebauer, Füller and Pezzei, 2013) or some universal motivations and inhibitors (Fuller, 2006; Heidenreich and Wittkowski, 2015) much less is known, so far, about the role of social and interpersonal mechanisms in motivating consumer co-creation participation (Roberts, Hughes and Kertbo, 2014). Further, prior research into consumer co-creation underestimates the relevance of enabling conditions, in terms of individual skills and opportunity needed to participate in the conversation with firms. These factors may be relevant constraints, especially in the online environment where consumers need additional skills to participate in virtual co-creation activities (Gruen, Osmonbekov and Czaplewski, 2006; Leung and Bai, 2013). The aim of this work is to provide an answer to these issues, by examining consumer engagement in co-creation activities from a novel perspective of motivation, opportunity and ability, by building on the Motivation-Opportunity-Ability (MOA) theory (MacInnis, Moorman and Jaworski, 1991). Such perspective accounts for both contextual and individual factors influencing consumers' behavior, hence providing a deeper understanding than theories that focus solely on consumer motivation. Further, it provides a deeper understanding of motivational factors, investigating interpersonal motivations, i.e. altruism and social reputation, to co-create.

Thus, the specific contribution of this research to existing knowledge is (i) to analyse the role of motivation, opportunity and ability on willingness to participate in communities of virtual co-creation (ii) to identify the interpersonal drivers of motivation to participate in communities of virtual co- 
creation. A better understanding of the conditions and skills needed to co-create would help in detecting and reducing potential constraints to participation. This will permit to a wider public to engage in such activities and experience the benefits deriving from the interaction and value creation with other consumers and the firm, above the utility created for the community as a whole. Further, a deeper comprehension of the interpersonal drivers of motivation may help in improving the consumer experience while engaging in co-creation activities and boosts the dialogue. The article proceeds as follow: section 2 presents the conceptual framework and hypotheses. Section 3 describes the methodology. Following results are presented. Finally, we discuss research implications and provide suggestions for future research.

\section{CONCEPTUAL FRAMEWORK}

The degree to which individuals process information is determined by three factors: motivation, opportunity and ability (MacInnis, Moorman and Jaworski, 1991). Motivation represents individuals' desire or readiness to process information, a force that directs individuals toward goals (Hoyer and MacInnis, 2007). It reflects the consumer's interest, readiness and desire to involve in information processing (MacInnis, Moorman and Jaworski, 1991). Opportunity is the extent to which the attention toward a topic is affected by limited time or distraction. It mirrors the extent to which a situation is favourable to the attainment of a goal (Jaworski and MacInnis, 1989) or the lack of constraints for achieving the goal (MacInnis, Moorman and Jaworski, 1991). Ability represents the consumer capabilities to engage in knowledge sharing, the extent to which consumers have the necessary resources, i.e. skills and knowledge, to achieve a desired outcome (MacInnis, Moorman and Jaworski, 1991; Hoyer and MacInnis, 2007). In our conceptual model, we propose that co-creation participation is facilitated by consumer ability and opportunity to engage in know-how exchange and motivation of doing so. We argue that motivation is influenced by interpersonal drivers, namely altruism and social reputation (Figure 1). 


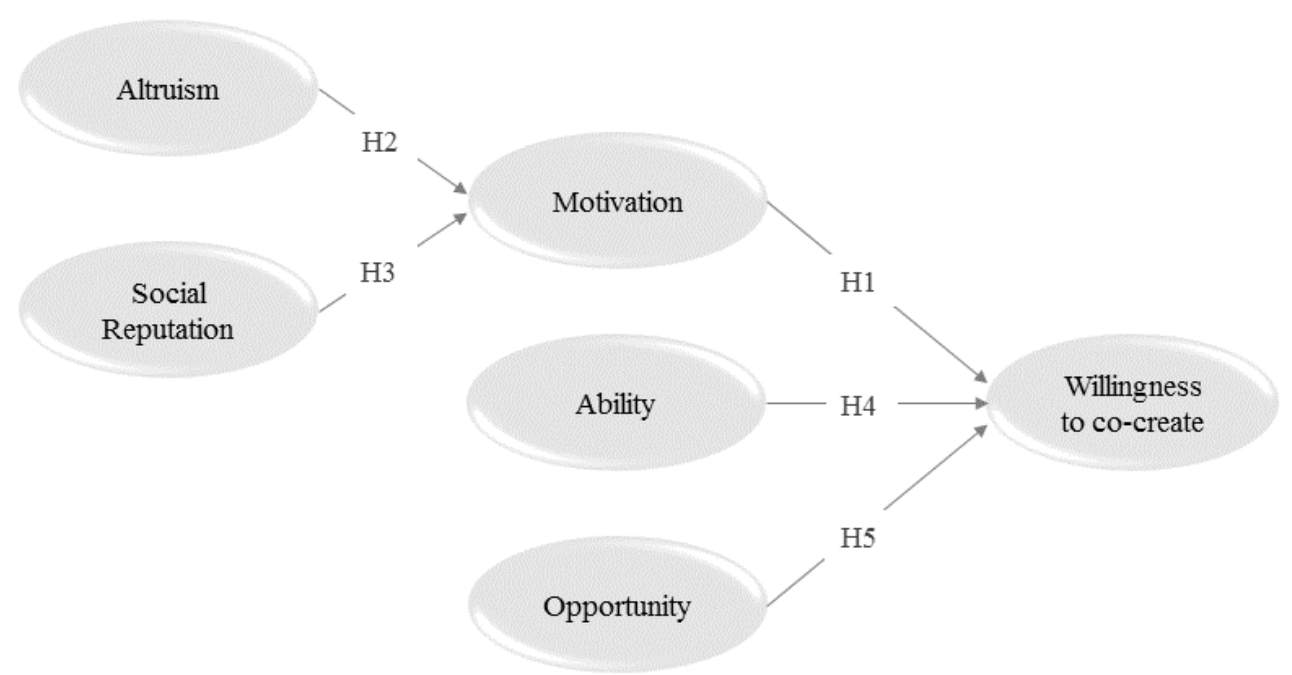

\subsection{Motivation}

Motivation is described as a force that directs individuals toward goals (Hoyer and MacInnis, 2007). It reflects readiness and interest to engage in information elaboration (MacInnis, Moorman and Jaworski, 1991). Motivation has been proved to be particularly relevant to explain online consumerto consumer know-how transfer that takes place among the customers of an organization's offering (Gruen, Osmonbekov and Czaplewski, 2005) and has been individuated as the main force in the MOA framework (Gruen, Osmonbekov and Czaplewski, 2006). The consumer contribution to joint innovation activities with firms depends on the intrinsic and extrinsic benefits that the individual can gain from it (Nambisan, 2002). Thus, we assume that motivation has a positive influence on willingness to co-create. More formally:

H1. Higher level of individual motivation leads to stronger willingness to participate in co-creation.

In the social exchange of information and know-how taking place during co-creation activities, social factors are likely to be strong motivational drivers (Kollock, 1999). In platforms devoted to discussion and networking, indeed, social motivations have been acknowledged as fundamental drivers of 
consumers motivation (Hars and Ou, 2002; Hennig-thurau et al., 2004; Feng and Morrison, 2007; Hsu and Lin, 2008; Xiang and Gretzel, 2010). According to social exchange theory individuals engage in the evaluation of the outcome that may derive from collaboration with other individuals (Wikström, 1996). Such knowledge sharing should be beneficial to each participant (Bagozzi 1975; Füller et al. 2006) otherwise the process of collaboration and sharing will likely fail. This is especially true in co-creation projects, devoted to the development of new products, that require a joint effort from multiple consumers providing knowledge, skills and effort for social exchange (Roberts, Hughes and Kertbo, 2014). Joint innovation activities are likely to be driven by the sharing of know-how among members and creation of social value (Holbrook, 2006) with relevant benefits to consumers (Wikström, 1996; Fuller, 2006).

Psychology and sociological studies acknowledge that social recognition represents a substantial driver of networking (Hwang, Kessler and Francesco, 2004) and a motivator for voluntary knowledge contribution (Bock et al., 2005; Kankanhalli, Tan and Wei, 2005). Individuals seeking social recognition, indeed, perceive greater utilities and benefits from participation in activities that increase their perception of being valuable for the community (Tesser, 1998; Dholakia, Bagozzi and Pearo, 2004). Consumers seek reputational gains and opportunities for recognition, esteem from peers and like-minded people (Harhoff, Henkel and Von Hippel, 2003; Shah, 2006). Social benefits includes status, image, good citizenship perception and connections with peers (Nambisan and Baron, 2009). Status and image could be enhanced through titles and public recognition, sources of pride for consumers, as they represent a symbol of uniqueness relative to other consumers (Hoyer et al., 2010).The individuals themselves may engage in self-enhancement actions, adopted to gain attention, show connoisseurship and knowledge, affirm status (Engel, Blackwell and Kegerreis, 1969) and enhance an individual image among other consumers (Sundaram, Mitra, \& Webster 1998). Further, engaging in the co-development of innovation offers individuals social image rewards able to strengthen their position among peers (Etgar, 2008). Hence, seeking of status and social esteem, could be an important motivational factor (Holbrook, 2006). Thus, we assume:

H2. Higher levels of perceived social reputation lead to stronger individual motivations

Co-creation engagement through creative contribution is likely to enhance intrinsic motivation (Etgar, 2008) positive affect (Burroughs and Mick, 2004) and enjoyment (Nambisan and Baron, 2009). Some consumers may participate purely for a sense of altruism, concern for others, a genuine desire to help and give useful information (Gruen, Osmonbekov and Czaplewski, 2006). People might be willing to assist others in need (Vergeer and Pelzer, 2010) providing mutual help and peer support (Moisander, Könkkölä and Laine, 2013) and may be motivated by the potential effects of their actions 
on social welfare (Bigné, Ruiz, Andreu, \& Hernandez 2013). Individuals' altruistic motivation has been acknowledged to be particularly relevant to encourage engagement is social networking (Kwon and Wen, 2010) open source projects (Hars and Ou, 2002) and in blogs (Hsu \& Lin, 2008). In social communities, individuals participation might be driven by the willingness to help other consumers in their purchase decisions, by providing suggestions, opinions and reviews on products or services (Balasubramanian and Mahajan, 2001; Hsu and Lin, 2008). Individuals engage in meaningful and altruistic activities with people that share analogous interests, desires and knowledge (Holbrook, 2006). In co-creation activities, consumers might participate as they genuinely believe in the altruistic objectives of the new product development effort or the improvement of existing products. In such context altruism may assume two faces (Sundaram et al. 1998): from one side, the information exchange might have the purpose to help others without anticipating any reward in return (Sundaram, Mitra and Cynthia, 1998); from the other side, the aim of the knowledge sharing could be to prevent others from experiencing the problems encountered by the consumer. In these activities, social value may be generated by the willingness to share in an altruistic way information and know-how with peers having similar interests (Holbrook, 2006). Hence:

H3. Higher levels of perceived altruism lead to stronger individual motivation.

\subsection{Ability}

Ability represents the extent to which individuals have the necessary resources, such as knowledge and skills, to achieve a desired goal (Hoyer and MacInnis, 2007). It refers to the individual's proficiency in performing the activity, that is under the individual's control (Batra and Ray, 1986). In the context of co-creation, we define ability as the member's skills or knowledge necessary to engage in know-how exchange with firms or other participants (Bonnemaizon and Batat, 2011). Highability individuals are able to process information more efficiently and are more proficient in the activity than individuals with lower abilities, because they possess relevant knowledge or expertise in the specific product or activity (Hallahan, 2001). They might be consumers that participated already in co-creation activities for the same or similar products, experts on the product or service object of the development process or knowledgeable about the specific activity to perform. These individuals could retrieve relevant knowledge about the task and are able to access that information easily because they use it more frequently (Hallahan, 2001). So, we hypothesize:

H4. Higher levels of individual ability lead to a stronger willingness to participate in co-creation

\subsection{Opportunity}


Opportunity represents the lack of situational or operational constraints to perform an activity (MacInnis, Moorman and Jaworski, 1991) or can alternatively be seen as the extent to which a situation enables to reach a desired outcome (Jaworski and MacInnis, 1989). One relevant advantage of virtual co-creation is the possibility of engaging in the activity and interacting with the community of consumers without time limitations or constraints and regardless of the place. This allows a geographical dispersion of participants and the possibility of asynchronous interaction among them (Gruen, Osmonbekov and Czaplewski, 2005). Consequently, opportunity in virtual co-creation is predominantly determined by the potential constraints experienced by consumers. In our context we define it in terms of time opportunity that is the availability of time to devote to co-creation activities on the side of the consumer. We expect that availability of time to devote to the co-creation activity will positively influence willingness to co-create. More formally:

H5. Higher levels of individual opportunity lead to stronger willingness to participate in co-creation

\section{METHODOLOGY}

To test our hypotheses we conducted an online survey among a population of 200 consumers where we measured the willingness to co-create and its drivers. We recruited respondents through an availability sampling (demographic statistics are reported in Appendix A and Appendix B), by distributing the survey to different communities of people from diverse nationalities. The purpose was to collect data across a sample of societies, representative of different cultures, to enable generalization of results across heterogeneous populations. The unit of analysis for our study is a virtual co-creation activity for food products. The choice of food products as unit of analysis has been made for several reasons. First of all, an increasing interest in food related issues can be easily noticed in the market, from the increasing number of TV cooking shows, to the fast development of a related offer of recipe books or cooking classes and the engagement of chefs in advertising campaigns. This trend attracts from one side a particular attention on food products by trendsetters and informed consumers while on the other side makes less interested consumers at least aware of the issue. Consumers all over the world are showing a growing understanding of the link between food consumption and health, are more attentive to the quality of their dietary choices and consequently responsive to health claims and to nutritional information on food labels (e.g. Williams 2005; Grunert \& Wills 2007). Secondly, food is one of the industry in which co-creation projects are particularly prosperous. For instance, Pickwick, an important tea manufacturer in the Netherlands, used cocreation in the whole process of NPD of Pickwick Tea 'Dutch Blend'. The Company involved customers in the development of a real Dutch tea, with a modern rejuvenating flavor. Consumers 
were involved in the development of the concept, chose the blend flavor, selected the product's name, developed the packaging design and were finally involved in the external communication about the product. San Carlo chips, in Italy, involved consumers in the development of a new taste for their chips. McDonald's launched in Germany, UK and Swiss a co-creation project "My Burger" in which consumers were invited to create their own burger (Lis and Horst, 2013; Liljedal and Dahlén, 2015). The winner burgers were then offered inside McDonald's restaurants. Thirdly, food co-creation does not generally require specific or advanced consumer competences or knowledge (consumers are generally asked to suggest new recipes, ingredients or tastes) as in the software or high-tech cocreation projects. That allows us to conduct the research among a wide array of individuals, not specifically developers or technicians.

\subsection{Measurements}

In the survey instrument, respondents were initially presented with a general definition and an example of co-creation in food products. Following, consumers were asked to answer to a series of questions about motivation, opportunity, ability and willingness to co-create, as well as altruism and social reputation. All constructs were adapted from prior literature. We measured motivation by adopting the three-item scale of Gruen et al. (2006), ability by the four-item scale of Gruen et al. (2006) and opportunity using a two-item scale adapted from Binney et al. (2003) and Bigné et al. (2013). Willingness to co-create (WTCC) was measured adapting the three-item scale of Siemsen et al. (2008). The antecedents of motivation were adapted from Hennig-Thurau \& Gwinner (2004), Bock et al. (2005) and Hsu \& Lin (2008). Specifically, we employed a three-item scale to measure altruism and a five-item scale to measure social enhancement. We collected demographic information as well.

\section{RESULTS}

After data detection we deleted twenty questionnaires due to incomplete and unreliable answers, obtaining 180 completed responses. We used Partial Least Squares Structural Equation Modeling (PLS-SEM), a second-generation multivariate data analysis method that permits to test linear and additive models. We opted for PLS-SEM due to the explorative type of research (Hwang et al., 2010; Wong, 2013). All our constructs were reflective.

\subsection{Measurement model}

We examined the reliability and validity of constructs through their outer loadings, composite reliability, AVE and AVE square root (Table 1). We assessed internal consistency reliability of constructs through composite reliability, a more appropriate indicator than Crobach's Alfa (Werts, Linn and Jöreskog, 1974). While Cronbach's Alfa assumes that all indicators are equally reliable, 
PLS prioritizes indicators according to their reliability, resulting in a more reliable composite. Internal consistency reliability was satisfying. Indicator Reliability was assured through mean of the squared outer loadings with the lowest indicator with a value of 0.62 . Convergent Validity, measuring the latent construct ability to explain a great share of the variance of its indicators was measured through AVE numbers. The lowest construct showed a value of 0.69 , higher than the suggested threshold of 0.5 (Bagozzi and Yi, 1988). We assessed discriminant validity with two criteria: (i) Fornell \& Larcker (1981) criterion, which assesses discriminant validity on the construct level and imposes the "square root" of AVE to be greater than the correlations among the latent variables. All our AVE square root were highly satisfying this condition; (ii) the loading of each indicator that is expected to be greater than all of its cross-loadings (Chin, 1998), evaluating discriminant validity on the indicator level. We satisfied this criterion as well.

Table 1 - Inter construct correlations and reliability measures ${ }^{a}$

\begin{tabular}{lllllllll}
\hline Construct & $\begin{array}{l}\text { Composite } \\
\text { Reliability }\end{array}$ & AVE & (1) & (2) & (3) & (4) & (5) & (6) \\
\hline (1) Ability & 0.74 & 0.92 & $\mathbf{0 . 8 6}^{\text {b }}$ & & & & & \\
\hline (2) Altruism & 0.73 & 0.89 & 0.69 & $\mathbf{0 . 8 6}$ & & & & \\
\hline (3) Motivation & 0.72 & 0.89 & 0.76 & 0.73 & $\mathbf{0 . 8 5}$ & & & \\
\hline (4) Opportunity & 0.77 & 0.87 & 0.05 & 0.09 & 0.05 & $\mathbf{0 . 8 8}$ & & \\
\hline (5) Social Reputation & 0.69 & 0.92 & 0.70 & 0.77 & 0.67 & -0.03 & $\mathbf{0 . 8 3}$ & \\
\hline (6) WTCC & 0.90 & 0.96 & 0.66 & 0.66 & 0.60 & 0.10 & 0.67 & $\mathbf{0 . 9 5}$ \\
\hline
\end{tabular}

$\mathrm{N}=180^{\mathrm{a}}$

bSquared correlations among constructs

\subsection{Structural model}

We ran 5000 bootstrap samples as suggested by Hair et al. (2011) ${ }^{1}$. The number of iterations to find convergence was 4, suggesting the goodness of the model. The model's predictive relevance has been assesses through Stone-Geisser's $Q^{2}$ (Geisser, 1974; Stone, 1974), using blindfolding procedures (Tenenhaus and Vinzi, 2005). Our constructs show values far above zero, thus confirming the predictive relevance of the constructs in the model. Figure 2 presents the results (detailed results are presented in Appendix C).

\footnotetext{
${ }^{1}$ Bootstrapping is a nonparametric technique for estimating standard errors of the model parameters (Efron and Tibshirani, 1993). In SmartPLS, the bootstrap procedure is employed to test the significance of a structural path using TStatistic(Wong, 2013).
} 




The inner model suggests that ability has the strongest influence on willingness to co-create, with a path coefficient of 0.48 ( $\mathrm{p}<0.001$ ), confirming H4. Motivation has a relevant effect as well with a path coefficient of 0.24 ( $\mathrm{p}<0.01$ ), according to H1. Opportunity, however, is not significant in influencing willingness to co-create, thus not confirming H5. Results indicate that both altruism and social reputation are antecedents of motivation, the first one with a stronger effect on motivation, thus confirming $\mathrm{H} 2$ and $\mathrm{H} 3$.

\subsection{Moderation effect}

We tested for potential moderations of age and gender by checking for interaction effects among the independent variables. In particular, we tested if both age and gender moderate the influence of motivation, ability and opportunity on willingness to co-create. Further, we tested if age and gender moderate the effect of altruism and social reputation on individual motivation. The PLS-product indicator approach has been applied to detect potential moderation effects. This approach estimates the interaction term by adding an additional latent variable in the structural model representing the product of the independent and the moderator variable (Henseler and Fassott, 2010). The direct 
relations of the independent and the moderator variables as well as the relations of the interaction terms with the dependent variables have been examined. To assess the moderation effects significance, bootstrap resampling procedures (Efron and Tibshirani, 1993) were performed. The results of 5000 resamples indicate that all paths coefficients were not significant for both age and gender. Thus, age and gender do not moderate the effect of social reputation and altruism on individual motivation and they do not moderate the effect of motivation, opportunity and ability on willingness to co-create.

\section{DISCUSSION}

Consumers are more and more engaged in co-creation activities developed by companies through their online communities. Our work offers a broad-scale guidance about which motives spur consumers in participating in such activity and at which conditions. First, our findings suggest that motivation and ability are two relevant drivers of co-creation. Differently from prior research, ability, not motivation, is the primary driver of willingness to co-create. Knowledgeable consumers are more willing to participate compared to low-ability individuals. This is a non-obvious result in the cocreation for food products, and potentially other industries, where the consumer does not need high technical or professional knowledge or skills to participate. Discovering such potential constraints is important, as firms can focus their attention and effort in improving this aspect. For instance, providing user friendly toolkits, short training to consumers or online support, by connecting consumers to experts via chat rooms, may improve their ability to share knowledge. Further, our findings show that opportunity seems not relevant in driving co-creation participation. This suggests that the opportunity cost of time dedicated to co-creation is not a primary constraint for consumers. Such an outcome is particularly interesting, as it suggests that the propensity to be involved in participative processes lies on believing to have something interesting to bring on the table. It is a kind of outcome that may have very intriguing consequences in many fields of social science, and that should be further studied in the future.

Motivation appears to be a significant driver of willingness to co-create. In particular, consumers' motivations are driven by both altruism and social reputation, where altruism plays a greater role. This result confirms that, in virtual communities, individual's motivations are likely to be driven by common goals, shared with peers. It is interesting to notice that such an outcome provides a further explanation to the reasons why ability emerges as more important than opportunity: as the main motivation in participation is related to altruism, the evaluation of the "outcome" of participation for the individual is associated more to how much the individual can give, rather than to what he can get. Consumers may believe to obtain a better outcome when their contribution has an intrinsic value 
(driven by skills and abilities) and seem spurred by the desire to help like-minded individuals, with similar passions and objectives. In this perspective, social benefits derived by consumers from their communicative behaviour inside virtual communities are apt to result in a total social interaction utility (Balasubramanian and Mahajan, 2001). Conversely, goal divergence within the community might be detrimental and lead to the failure of joint innovation projects. Thus, companies need to develop platforms and instruments with the objective of facilitating and enhancing the information sharing and highlight the importance of consumer's contribution for the social well-being. For instance, the provision of discussion forums, chat rooms and newsgroups may strengthen consumer relationships and engagement. Besides altruism, also social reputation impacts on individual's motivations. It reflects the willingness to emerge from the community and being recognized for his own skills, knowledge and ideas by peers. It reflects the perceived social status inside the community. Such a result suggests a twofold interpretation: on the one hand, individuals seem more motivated to co-create whereas they perceive the opportunity to receive some social recognition in case of an effective contribution. This enriches the understanding of the underlying objective of participation, i.e. first and foremost to provide a contribution, but also the possibility to perceive that such a contribution is appreciated by the others. On the other hand, the importance of not being exposed to reputational drawbacks in case of community rejection of the contribution, in order to preserve the self-perceived status in the community. Consequently, companies will need to recognize the consumer paternity of ideas, such as through public awards and prizes or by rewarding consumers that offer valuable contributions by providing a special status inside the community. Additionally, they need to protect consumer privacy, by providing anonymity in the extend the consumer requires it (e.g. using nicknames), to not expose them at risks such as being recognized if the product fails or is not accepted. Further, companies should enable individuals to establish relational bonds inside the community and maintain ongoing relationships with their peers, for instance by organizing social events within the community. Thus, from a motivational perspective both altruism and social reputation enable the joint innovation and should be directed to the same end that is the collective creation of value. This is especially true in virtual communities that can be more effective in the process of value exchange, as the Internet provides a dynamic, multimedia, and interactive channel for communication (Hung and Li, 2007).

\section{CONCLUSIONS, LIMITATIONS AND FUTURE RESEARCH}

In this work we have analyzed consumers' willingness to participate in online communities for cocreating food products. To do this, we have adopted a MOA perspective and, through an empirical experiment, we have highlighted how ability is a stronger antecedent of willingness to participate 
than opportunity and that altruism and social reputation coexist as motivating factors, with a stronger relevance of the former. These outcomes, that suggested several theoretical and practical implications presented in the discussion, provide a richer understanding of the mechanisms encouraging individuals in participating in virtual co-creative communities. Findings suggest that MOA may actually be valid and provides insightful theoretical lenses through which observing such an emerging trend as co-creation.

Like all studies of this kind, there are a number of limitations to this work. First of all, the scales we used, although already validated in prior studies, should be further tested in the specific context of research. Despite indicator reliability was assured through mean of the squared outer loadings, our lowest indicator had a value of 0.62, slightly below the threshold commonly suggested of 0.7. Secondly, our data were collected through a survey, thus experimental manipulations were not performed. Hence, we cannot claim to provide direct evidence of the individual mental process investigated. Experimental studies could be useful to this end. Above that, a further limitation of our methodology lies in the use of "willingness to co-create" as the decision-making outcome of our model, but not the actual behavior. Thus, a longitudinal study might be useful to study if participants actually engage in co-creation activities. Finally, it may be possible that co-creation activities deployed in other industries would have shown different results. Since we only tested our model in one industry, we cannot rule out the possibility that our results are influenced by peculiarities of this context. Hence, we suggest that future studies will investigate the role of motivation, ability and opportunity for different industries, to test the generalizability of the model.

\section{ACKNOWLEDGMENT}

We would like to thank Parisa Bakhtiari Koshkojani and two anony- mous for their support in the development of the paper.

\section{REFERENCES}

Bagozzi, R. P. (1975) 'Social exchange in marketing', Journal of the Academy of Marketing Science, 3(3-4), pp. 314-327.

Bagozzi, R. P. and Yi, Y. (1988) 'On the evaluation of structural equation models', Journal of the academy of marketing science, 16(1), pp. 74-94.

Balasubramanian, S. and Mahajan, V. (2001) 'The Economic Leverage of the Virtual Community', International Journal of Electronic Commerce, 5(3), pp. 103-138.

Batra, R. and Ray, M. (1986) 'Situational effects of advertising repetition: The moderating influence of motivation, ability, and opportunity to respond', Journal of Consumer research, 12(4), pp. 432445.

Bigné, E., Ruiz, C., Andreu, L., \& Hernandez, B. (2015) 'The role of social motivations, ability, and opportunity in online know-how exchanges: evidence from the airline services industry', Service 
Business, 9(2), pp. 1-24.

Binney, W., Hall, J. and Shaw, M. (2003) 'A further development in social marketing application of the MOA framework and behavioral implications', Marketing Theory, 3(3), pp. 387-403.

Bock, G. et al. (2005) 'Behavioral intention formation in knowledge sharing: Examining the roles of extrinsic motivators, social-psychological forces, and organizational climate', MIS quarterly, 29(1), pp. 87-111.

Bonnemaizon, A. and Batat, W. (2011) 'How competent are consumers? The case of the energy sector in France', International Journal of Consumer Studies, 35(3), pp. 348-358.

Brodie, R. J. et al. (2013) 'Consumer Engagement in a Virtual Brand Community: An Exploratory Analysis Consumer engagement in a virtual brand community : An exploratory analysis', Journal of Business Research, 66(1), pp. 105-114.

Burroughs, J. E. and Mick, D. G. (2004) 'Exploring antecedents and consequences of consumer creativity in a problem-solving context', Journal of Consumer Research, 31(2), pp. 402-411.

Casaló, L., Flavián, C. and Guinalíu, M. (2010) 'Relationship quality, community promotion and brand loyalty in virtual communities- Evidence from free software communities', International Journal of Information Management, 30(4), pp. 357-367.

Chin, W. (1998) 'The partial least squares approach to structural equation modeling', Modern methods for business research, 295(2), pp. 295-336.

Dholakia, U., Bagozzi, R. and Pearo, L. (2004) 'A social influence model of consumer participation in network-and small-group-based virtual communities', International Journal of Research in Marketing, 21(3), pp. 241-263.

van Dijk, J., Antonides, G. and Schillewaert, N. (2014) 'Effects of co-creation claim on consumer brand perceptions and behavioural intentions', International Journal of Consumer Studies, 38(1), pp. $110-118$.

Efron, B. and Tibshirani, R. J. (1993) An Introduction to the Bootstrap. CRC Press.

Engel, Blackwell and Kegerreis (1969) 'How information is used to adopt an innovation', Journal of Advertising Research, 9(4), pp. 3-8.

Etgar, M. (2008) 'A descriptive model of the consumer co-production process', Journal of the Academy of Marketing Science, 36(1), pp. 97-108.

Feng, R. and Morrison, A. M. (2007) 'Quality and value network marketing travel clubs', Annals of Tourism Research, 34(3), pp. 588-609.

Fornell, C. and Larcker, D. (1981) 'Evaluating structural equation models with unobservable variables and measurement error', Journal of marketing research, 18(1), pp. 39-50.

Fuller, J. (2006) 'Why consumers engage in virtual new product developments initiated by producers', Advances in Consumer Research. Associatio. Edited by D. Connie Pechmann and Linda Price, 33, pp. 639-646.

Füller, J. et al. (2006) 'Community based innovation: How to integrate members of virtual communities into new product development', Electronic Commerce Research, 6(1), pp. 57-73.

Füller, J. (2010) 'Refining Virtual Co-Creation from a Consumer Perspective', California Management Review, 52(2), pp. 98-122.

Gebauer, J., Füller, J. and Pezzei, R. (2013) 'The dark and the bright side of co-creation: Triggers of member behavior in online innovation communities', Journal of Business Research. Elsevier Inc., 66(9), pp. 1516-1527.

Geisser, S. (1974) 'A predictive approach to the random effect model', Biometrika, 61(1), pp. 101- 
107.

Gruen, T., Osmonbekov, T. and Czaplewski, A. (2005) 'How e-communities extend the concept of exchange in marketing: an application of the motivation, opportunity, ability (MOA) theory', Marketing Theory, 5(1), pp. 33-49.

Gruen, T., Osmonbekov, T. and Czaplewski, A. (2006) 'eWOM: The impact of customer-to-customer online know-how exchange on customer value and loyalty', Journal of Business research, 59(4), pp. $449-456$.

Grunert, K. and Wills, J. (2007) 'A review of European research on consumer response to nutrition information on food labels', Journal of Public Health, 15(5), pp. 385-399.

Hair, J., Ringle, C. and Sarstedt, M. (2011) 'PLS-SEM: Indeed a silver bullet', Journal of Marketing Theory and Practice, 19(2), pp. 139-152.

Hallahan, K. (2001) 'Enhancing motivation, ability, and opportunity to process public relations messages', Public Relations Review, 26(4), pp. 463-480.

Harhoff, D., Henkel, J. and Von Hippel, E. (2003) 'Profiting from voluntary information spillovers: How users benefit by freely revealing their innovations', Research Policy, 32(10), pp. 1753-1769.

Hars, A. and Ou, S. (2002) 'Working for free? Motivations of participating in open source projects', International Journal of Electronic Commerce, 6(3), pp. 25-39.

Heidenreich, S. and Wittkowski, K. (2015) 'The dark side of customer co-creation: exploring the consequences of failed co-created services', Journal of the Academy of Marketing Science, 43(4), pp. 279-296.

Hennig-thurau, T. et al. (2004) 'Electronic word-of-mouth via consumer-opinion plaforms: what motives consumers to articulate themselves on the Internet?', Journal of Interactive Marketing, 18(1), pp. 38-52.

Hennig-Thurau, T. and Gwinner, K. (2004) 'Electronic word-of-mouth via consumer-opinion platforms: What motivates consumers to articulate themselves on the Internet?', Journal of Interactive Marketing, 18(1), pp. 34-52.

Henseler, J. and Fassott, G. (2010) 'Testing moderating effects in PLS path models: An illustration of available procedure', in Handbook of Partial Least Squares. Springer Berlin Heidelberg, pp. 171193.

Hoffman, D., Kopalle, P. and Novak, T. (2010) "The "right" consumers for better concepts: Identifying consumers high in emergent nature to develop new product concepts', Journal of Marketing Research, 47(5), pp. 854-865.

Holbrook, M. (2006) 'Consumption experience, customer value, and subjective personal introspection: An illustrative photographic essay’, Journal of Business Research, 59(6), pp. 714-725.

Hoyer, W. D. et al. (2010) 'Consumer Cocreation in New Product Development', Journal of Service Research, 13(3), pp. 283-296.

Hoyer and MacInnis (2007) Consumer behavior. Boston’ Houghton Mifflin;

Hsu, C. and Lin, J. (2008) 'Acceptance of blog usage: The roles of technology acceptance, social influence and knowledge sharing motivation', Information \& management, 45(1), pp. 65-74.

Hung, K. H. and Li, S. Y. (2007) 'The Influence of eWOM on Virtual Consumer Communities:Social Capital,Consumer Learning, and Behavioral Outcomes', Journal of Advertising Research, 47(4), pp. 485-495.

Hwang, A., Kessler, E. and Francesco, A. (2004) 'Student networking behavior, culture, and grade performance: an empirical study and pedagogical recommendations', Academy of Management 
Learning \& Education, 3(2), pp. 139-150.

Hwang, H. et al. (2010) 'A comparative study on parameter recovery of three approaches to structural equation modeling', Journal of Marketing Research, 47(4), pp. 699-712.

Jaworski, B. and MacInnis, D. (1989) 'Marketing jobs and management controls: toward a framework', Journal of Marketing Research, 26(4), pp. 400-419.

Kankanhalli, A., Tan, B. C. Y. and Wei, K. (2005) 'Contributing knowledge to electronic knowledge repositories: An empirical investigation', 29(1), pp. 113-143.

Kollock, P. (1999) 'The economies ol online cooperation', Communities in cyberspace, p. 220.

Kwon, O. and Wen, Y. (2010) 'An empirical study of the factors affecting social network service use', Computers in Human Behavior, 26(2), pp. 254-263.

Leung, X. and Bai, B. (2013) 'How motivation, opportunity, and ability impact travelers' social media involvement and revisit intention', Journal of Travel \& Tourism Marketing, 30(1-2), pp. 58-77.

Liljedal, K. T. and Dahlén, M. (2015) 'Consumers' response to other consumers' participation in new product development', Journal of Marketing Communications, pp. 1-13.

Lis, B. and Horst, M. (2013) 'Electronic Word of Mouth Impacts: A Spotlight on Customer Integration', Business \& Information Systems Engineering, 6(1), pp. 63-65.

Lusch, R. and Vargo, S. (2006) 'Service-dominant logic: Reactions, reflections and refinements', Marketing Theory, 6(3), pp. 281-288.

MacInnis, D., Moorman, C. and Jaworski, B. (1991) 'Enhancing and measuring consumers' motivation, opportunity, and ability to process brand information from ads', The Journal of Marketing, 55(4), pp. 32-53.

Merrilees, B. (2016) 'Interactive brand experience pathways to customer-brand engagement and value co-creation', Journal of Product \& Brand Management, 25(5), pp. 402-408.

Moisander, J., Könkkölä, S. and Laine, P. M. (2013) 'Consumer workers as immaterial labour in the converging media markets: Three value-creation practices', International Journal of Consumer Studies, 37(2), pp. 222-227.

Nambisan, S. (2002) 'Designing virtual customer environments for new product development: Toward a theory', Academy of Management Review, 27(3), pp. 392-413.

Nambisan, S. and Baron, R. A. (2009) 'Virtual customer environments: Testing a model of voluntary participation in value co-creation activities', Journal of Product Innovation Management, 26(4), pp. 388-406.

O’Hern, M. and Rindfleisch, A. (2009) 'Customer co-creation', in Malhotra, N. K. (ed.) Review of marketing research. 6th edn. Emerald Group Publishing Limited, pp. 84-106.

Orcik, A., Teodora, S. and Freund, R. (2013) 'Co-creation: examples and lessons learned from southeast Europe', in The 6th International Conference for Entrepreneurship, Innovation and Regional Development - ICEIRD At Istanbul, Turkey.

Roberts, D., Hughes, M. and Kertbo, K. (2014) 'Exploring consumers' motivations to engage in innovation through co-creation activities', European Journal of Marketing, 48(1/2), pp. 147-169.

Sawhney, M. (2005) 'Collaborating to create: The Internet as a platform for customer engagement in product innovation', Journal of Interactive Marketing, 19(4), pp. 4-17.

Sawhney, M. and Prandelli, E. (2000) 'Communities of Creation: managing distributed innovation in turbulent markets', California Management Review, 42(4), pp. 24-54.

Shah, S. K. (2006) 'Motivation, Governance, and the Viability of Hybrid Forms in Open Source Software Development', Management Science, 52(7), pp. 1000-1014. 
Siemsen, E., Roth, A. and Balasubramanian, S. (2008) 'How motivation, opportunity, and ability drive knowledge sharing: The constraining-factor model', Journal of Operations Management, 26(3), pp. 426-445.

Stone, M. (1974) 'Cross-validatory choice and assessment of statistical predictions', Journal of the Royal Statistical Society. Series B (Methodological), 36(2), pp. 111-147.

Sundaram, D. S., Mitra, K. and Cynthia, W. (1998) 'Word-of-Mouth Communications: A Motivational Analysis.', Advances in consumer research, 25(1), pp. 527-531.

Tenenhaus, M. and Vinzi, V. (2005) 'PLS path modeling', Computational statistics \& analysis, 48(1), pp. 159-205.

Tesser, A. (1998) 'Toward a self-evaluation maintenance model of social behavior', Advances in Experimental Social Psychology, 21, pp. 181-227.

Vergeer, M. and Pelzer, B. (2010) 'Consequences of media and Internet use for offline and online network capital and well-being. A causal model approach.', Journal of Computer-Mediated, 15(1), pp. 189-210.

Vernette, E. and Hamdi-Kidar, L. (2013) 'Co-creation with consumers: who has the competence and wants to cooperate?', International Journal of Market Research, 55(4), pp. 2-20.

Werts, C., Linn, R. and Jöreskog, K. (1974) 'Intraclass reliability estimates: Testing structural assumptions', Educational and Psychological measurement, 34(1), pp. 25-33.

Wikström, S. (1996) 'Value creation by company-consumer interaction', Journal of Marketing Management, 12(5), pp. 359-374.

Williams, P. (2005) 'Consumer understanding and use of health claims for foods', Nutrition Reviews, 63(7), pp. 256-264.

Wong, K. (2013) 'Partial least squares structural equation modeling (PLS-SEM) techniques using SmartPLS', Marketing Bulletin, 24(1), pp. 1-32.

Xiang, Z. and Gretzel, U. (2010) 'Role of social media in online travel information search', Tourism management, 31(2), pp. 179-188.

\section{APPENDIX A}

\section{Demographic statistics $^{a}$}

\begin{tabular}{ll|lr}
\hline Gender & & Education & \\
\hline Male & $64.4 \%$ & High School & $19.4 \%$ \\
\hline Female & $35.6 \%$ & 5-years Master & $71.1 \%$ \\
\hline Age & & Ph.D & $9,4 \%$ \\
\hline $18-27$ & $48.3 \%$ & & \\
\hline $28-35$ & $35 \%$ & & \\
\hline $36-45$ & $4.4 \%$ & & \\
\hline 46 or over & $12.2 \%$ & & \\
\hline
\end{tabular}

$\mathbf{N}=$ 180 $^{a}$

\section{APPENDIX B}




\begin{tabular}{ll|ll}
\hline \multicolumn{3}{l}{ Demographic statistics - Nationality } & \\
\hline Europe & $\mathbf{4 6 , 7 \%}$ & Asia & $\mathbf{4 2 , 2 \%}$ \\
\hline Austria & $1,1 \%$ & Bangladesh & $0,6 \%$ \\
\hline England & $2,2 \%$ & India & $1,7 \%$ \\
\hline Finland & $5 \%$ & Iran & $38,9 \%$ \\
\hline France & $0,6 \%$ & Nepal & $0,6 \%$ \\
\hline Germany & $18,9 \%$ & Vietnam & $0,6 \%$ \\
\hline Italy & $16,7 \%$ & North America & $\mathbf{1 0 \%}$ \\
\hline Portugal & $0,6 \%$ & Canada & $0,6 \%$ \\
\hline Spain & $0,6 \%$ & United States & $9,4 \%$ \\
\hline Sweden & $1,1 \%$ & NA & $\mathbf{1 , 1 \%}$ \\
\hline N=180 & & &
\end{tabular}

\section{APPENDIX C}

\begin{tabular}{lll}
\hline \multicolumn{2}{l}{ Results summary for structural model $^{\mathbf{a}}$} & \\
& Path $^{\text {coeff }}$ & SE \\
\hline Motivation $\rightarrow$ WTCC & $0.24^{* *}$ & 0.08 \\
\hline Ability $\rightarrow$ WTCC & $0.48^{* * *}$ & 0.08 \\
\hline Opportunity $\rightarrow$ WTCC & 0.06 & 0.07 \\
\hline Social reputation $\rightarrow$ Motivation & $0.26^{* *}$ & 0.09 \\
\hline Altruism $\rightarrow$ Motivation & $0.54^{* * *}$ & 0.09 \\
\hline & $\boldsymbol{R}^{\wedge} 2$ & $\boldsymbol{Q}^{\wedge} \mathbf{2}$ \\
\hline Motivation & 0.56 & 0.41 \\
\hline WTCC & 0.47 & 0.42 \\
\hline $\mathbf{N}=\mathbf{1 8 0}^{\mathbf{a}}$ & & \\
\hline
\end{tabular}

This is the accepted version of the following article: Bettiga D, Lamberti L, Noci G. Investigating social motivations, opportunity and ability to participate in communities of virtual co-creation. Int J Consum Stud. 2018;42:155-163., which has been published in final form at https://doi.org/10.1111/ijcs.12409. This article may be used for non-commercial purposes in accordance with the Wiley Self-Archiving Policy. 